\title{
A Self-Learning Knowledge Based System for Credit Evaluation of Loan Application: The Case of Commercial Bank of Ethiopia
}

\author{
Wesenu Bekele Mulatu ${ }^{1} \quad$ Mebratu Fana Bedasa ${ }^{2} \quad$ Asrat Sime Bedada $^{2}$ \\ 1.Department of Information System, College of Computing, Madda Walabu University, Bale Robe, Ethiopia \\ 2.Department of Computer Science, College of Computing, Madda Walabu University, Bale Robe, Ethiopia
}

\begin{abstract}
This study on prototype self-learning knowledge based system (KBS) is focused on evaluation of loan application used to overcome the challenges that resulted from lack of domain experts and poor loan evaluations. We attempted to design and develop a prototype self-learning KBS that provide advisory services for any credit customers and assists the domain experts in evaluation of customer's requests for the loan. To develop this prototype system, knowledge was acquired using semi-structured interview from domain experts which are selected using purposive sampling technique from Commercial Bank of Ethiopia (CBE) and critique the acquired knowledge. Explicit knowledge is acquired by analyzing the secondary source of knowledge by method of document analysis. Then, the acquired knowledge is modeled using decision tree that represents concepts and procedures involved in credit evaluation and production rules are used to represent the domain knowledge. The prototype system is implemented using SWI Prolog editor tool. To determine the applicability of the prototype system in the domain area, the system has been evaluated and tested by the domain experts. Eighteen (18) test cases were selected purposively. Test cases are equally selected from both ineligible and eligible cases. The overall total performance of the prototype system is $77.71 \%$. The performance of the prototype system is hopeful and meets the objective of the study. The study concludes that the major credit production type that advanced to customer is import letter of credit facility, export credit facility, pre-shipment credit facility and merchandise. The eligibility of application is focused on general and specific criteria. Credit customer is classified as business, corporate and commercial based on the score sheet they achieved. Generally, in this study, the applicability of knowledge of prototype self-learning KBS is proved as hopeful approach in banking industry for credit evaluation.
\end{abstract}

Keywords: KBS, self-learning and credit (loan).

DOI: $10.7176 / \mathrm{IKM} / 10-6-03$

Publication date:September $30^{\text {th }} 2020$

\section{Introduction}

Banks are financial institutions that accept deposit and make loans. Its role in the economy of any country is very significant. Availing credit to borrowers is one means by which banks contribute to the growth of economy. CBE extends credit (loan) to different types of borrower for many different purposes. When banks extend credit to the borrowers, it is important to evaluate borrower's credit application carefully to reduce risks that come due to poor loan assessment [1]. Credit evaluation and approval is the process of business or an individual must go through to become eligible for a loan or to pay for goods and services over an extended period. It is also the process businesses or lenders undertake when evaluating an applications. Granting credit approval depends on the willingness of the creditor to lend money in the current economy. It also depends on assessment of the ability and willingness of the borrower to return the money or pay for the goods obtained and interest in an appropriate manner [2]. In doing such boring and complex tasks, a bank has a high probability expose to risks because of credit scoring evaluation process depends on domain experts who are accountable for assessment of the credit applications and making decision to accept or to reject it. The credit risk has long been an important and widely studied topic in banking. For lots of Commercial Bank, the credit risk remains the most important and difficult risk to manage and evaluate. To managing and analyzing data in bank system and preventing different risks, building robust and efficient technologies using Artificial Intelligence (AI) and Expert systems (ES) are very important [3] [4] [5] [6]. The use of KBS should encourage the systematic and thoughtful assessment of loan applications without the need for time consuming supervision by more experienced officers. Finally, the knowledge base is easily updated and maintained the basic information of borrowers. In this study, we developed a low-cost automated self-learning KBS fitting in the skills of credit evaluator experts to help domain experts within evaluation of loan application and provide advisory services for any credit customers.

\section{Problem Identification}

In developing counties like Ethiopia, bank plays great role in growth by encouraging saving culture as well as lending to individual or sector in order to run the business. Currently, the banking business is so sensitive because more of their income (revenue) will be generated from credit (loan) given to their customers [1].This credit creation process exposes the banks to high credit risk which leads to loss. Without effective credit risk management, good bank performance or profit is not efficiently generated. In order to minimize this risk, it is necessary that procedures 
and control mechanisms are in place to ensure each loan accurately assessed and the bank's total loan portfolio does not compromise the bank's overall integrity. That is, the financial soundness of a bank is largely dependent on the riskiness of its loan portfolio [5].In CBE, each individual loan applicant is assigned to customer relationship manager for the purpose of evaluation of their application. This is very difficult and time consuming in the case of more applicants. These problems become worse due to the scarcity of domain experts. Because of this, bank can lose a lot of customers. Moreover, in CBE, loan applicants can be issued only at head office and district. As a result, customers are expected to travel long distances to their nearest head office or bank district in order to get loan service. Most of the rural people of Ethiopia travel along distances to reach their nearest bank district. Since they travel a long distance, they are forced to spend more costs. Due to this, lots of people in rural areas are limited from these services. Implementing computing technology for delivering of financial services is one way banks can reduce cost and possibility of loan defaults. However, the CBE currently have no well implemented KBS technology. The major advantage in automating loan evaluations is the improvement in the bank's lending record through the uniform application of credit and security guidelines [5] [7]. Hence, to overcome the above problems, we motivated to design and develop self-learning KBS incorporating the skills of domain experts to assist credit evaluator or officer in a credit evaluation as well as provide advisory services for credit applicant requirements.

\section{Related Works}

Some of the related works conducted by foreign and local researchers have been reviewed as follows.

Kay Bryant [5] was study the integration of qualitative factors into ESs for evaluating agricultural loans. The main goal of this study is to examine whether ES technology is an effective and efficient means of providing advice and support for the agricultural loan evaluation process. He tries to incorporate qualitative factor such as a loan officer's intuition, experience and judgment as well as quantitative factors. In this paper, knowledge is extract from two bank institution of loan officers through questionnaires and the acquired knowledge is represented using dependency diagram. The developed ES system enables the loan officer's to make decision easily in agricultural loan evaluation. The author concludes that ES is required to lower operating costs and increase productivity as well as profits. All of the loan officers regarded the ES is highly being useful and effective. This finding has particular relevance for the less experienced loan officers who found the expert system most useful.

According to [8] survey conducted in British banking industry on how ES technology is being used in banking sector and how it affects banking organizations. According to this work, $66.7 \%$ where used ES in banking; which is take high percentages and $23.8 \%$ are not using this technology in banking. The rest percent which is $9.5 \%$ are planning to use ESs. As the results of this study indicate, $50 \%$ secretarial staff is actual ES users. The next are middle management.

Desalegn [9] has done research on designing a KBS for VAT (Value Add Tax) administration. The main focus of the study is to explore and design an applicable KBS that support the stakeholders of tax by providing appropriate VAT related advice based on the tax law of the country and working procedures of the concerned bodies. The developed prototype knowledge is extracted from documented and non-documented sources of knowledge and from domain experts of VAT administration. The KBS of the system contains the domain knowledge for solving VAT refund related problem. The knowledge is represented as a set of rules and facts. Each rule specifies a relationships, recommendation, directive, strategy or heuristic and has the IF (condition) THEN (action) structure. In this study, he used SWI prolog tool to develop rule based KBS because of its suitability for the production rule and capacity to minimize the complexity of the problem. After developing the prototype of the system, testing of the prototype rule based system for VAT administration was done to evaluate the performance of the system. According this study, the author found accuracy of $82.5 \%$.

Wondimagegnehu [10] has conducted research study on determinants of non-performing loans the case of CBE. The objective of this study was to identify and investigate the determinants of non-performing loans of Banks. In this study the survey technique were used. The two approaches of research qualitative and quantitative approach were applied. As the researcher found out, the factor that neglect loans of banks to borrower are poor credit assessment, failed loan monitoring, underdeveloped credit culture, weak institutional capacity, unfair competition among banks, relaxed credit term and condition and default by borrowers and their knowledge limitation.

Josephine Nassali [11] has conducted a research on a Loan Assessment System for Centenary Rural development Bank (LASCRDB). The main objectives of the study is to design a loan assessment system that can be used to overcome the challenges being experienced in Uganda's financial institutions as a result of lack of good decision making mechanisms in disbursing loans. In order to address the problem, a structured approach to analysis and design of systems was followed in the development of the prototype in the study. The main methodology used in the study was the research approach where an interview guide was designed to elicit data required on critical issues towards establishing a LASCRDB. The qualitative research methods were used in the study and to examine the nature of loan assessment system in Ugandan financial institutions. In the study different methods of data collection were involved. These included, an interview guide, observation and reviewing of existing data on the 
loan assessment system. The findings of the study showed that, the loan assessment system in place is time consuming as it takes too long (up to a month) for a loan to be approved and the amount approved is too little (sometimes less than 50 percent) compared to what a client applies for. As the result of the study showed that the officers also identified these as complaints raised by a big percentage of customers and revealed that this is as a result of bias which is inherent in individuals.

Martin Omara [12] has conducted study on credit assessment process and repayment of Bank Loans in Barclays Bank Uganda Ltd. The main objective of the study was to examine the appropriateness of credit assessment process used by Barclays Bank Uganda Ltd; to establish the level of loan default on Barclays Bank performance and to design strategies on how credit assessment and repayment of Bank loans can be improved. The research was a case study of Barclays Bank Uganda Ltd with a sample size of 73 respondents comprising staff and customers of Barclays. As the researcher found out, there was delay by Barclays Bank in scoring loans. The Barclays charged commitment fees to both new and existing borrowers. As result found implies that Bank was found to charge higher interest rate than the competitor. The Bank also did not do proper monitoring and follow up of loans once disbursed. The result found shows that Barclays was not to have a central reference point where records about customer borrowing from other financial institutions are kept.

From the review made, one can understand that there is no research conducted to design self-learning KBS for credit evaluation. So, the proposed a prototype self-learning KBS in this study is conducted to explore the applicability of a self-learning KBS for credit evaluation of loan applications. The main objective of the study was to evaluate loan application or requests align within the rule and procedure of credits. Therefore, the proposed self-learning KBS can assist domain expert during loan evaluation process and credit customer by providing advisory services.

\section{System Architecture and Implementation Tool}

A KBS tool is a collection of software instructions and utilities taken to be a software package designed to support the development of KBS. KBS can be built using programming languages like LISt Processing (LISP) and PROgramming in LOGIC (Prolog) [13].

\subsection{Implementation Tool}

WIN-PROLOG provides a complete development environment including easy-to-use pull-down menus, support for multiple edit windows and rich edit (e.g. automatic syntax coloring, multiple fonts in a window, etc.). It allows you to create polished windows applications and provides an extensive range of graphics predicates allowing convenient access to a large number of windows Graphical User Interface (GUI) functions [11]. Some of the most common domain areas of Prolog are environmental modeling, sales modeling, medical domain, fungus identification, image recognition, management consultancy, etc. it has the ability to change its program whilst that program is running and it relates to a logic called predicate calculus [14] [15].

\subsection{System Architecture}

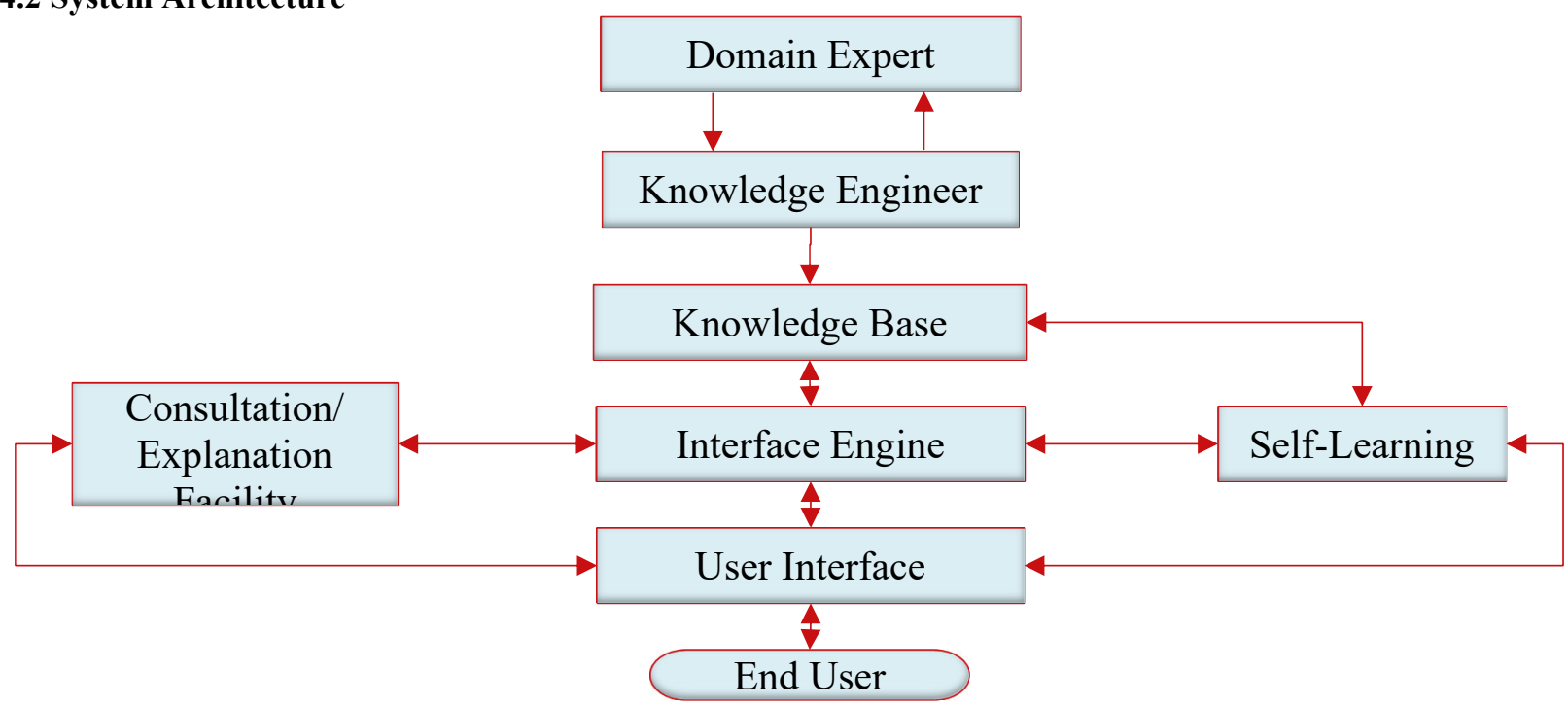

Figure 4.1. Architecture of the prototype self-learning KBS

\subsection{Knowledge Base}

Knowledge base is a set of rules or the encoded knowledge about credit evaluation of the prototype system. The 
validated knowledge is represented in the form of rules by rule-based representation technique and the rules are codified to the knowledge base of the prototype system using Prolog programming language [16]. Sample rules in the knowledge base of the prototype system are discussed as follows.

Rule: - Rule for overdraft credit production type:

(The applicant's business operation is $>=2$ years)AND

(The applicant's current account $>=1$ year) AND

(Applicant's advanced a term loan $>=1$ ), write ('the applicant is Eligible for Overdraft Credit'), assertz (request (Name, Type)),

tell('best.pl'),write(':-dynamic(request/2).'),listing(request),told;write('the applicant is not eligible For Overdraftcredit'), assertz(request(Name, Type)), tell('best.pl'),

write(':-dynamic(request/2).’),listing(request), told.

\subsection{Fact Base}

In this study, we used elements of the facts base of the prototype system in the following sample format: request (Name, Type) \%\%predicate of fact base

request(hailu, overdraft) $\% \%$ to represent the fact that hailu requests or apply for overdraft credit production type. request(abebe, pre-shipment) $\% \%$ to represent the fact that abebe requests for pre-shipment credit production type. Cust_clas(Name,Btype) $\quad \% \%$ predicate of fact base for credit customer classification Cust_clas(abel, business) $\quad \% \%$ to represent the fact that abel is classified a business credit customer.

\subsection{Interface Engine}

The developed prototype system provides advising services to both new and existing customers of the bank. The customers of the bank got advising on requirement and criteria which is expected from them. Figure 4.2 below, shows advisory service for new customer.

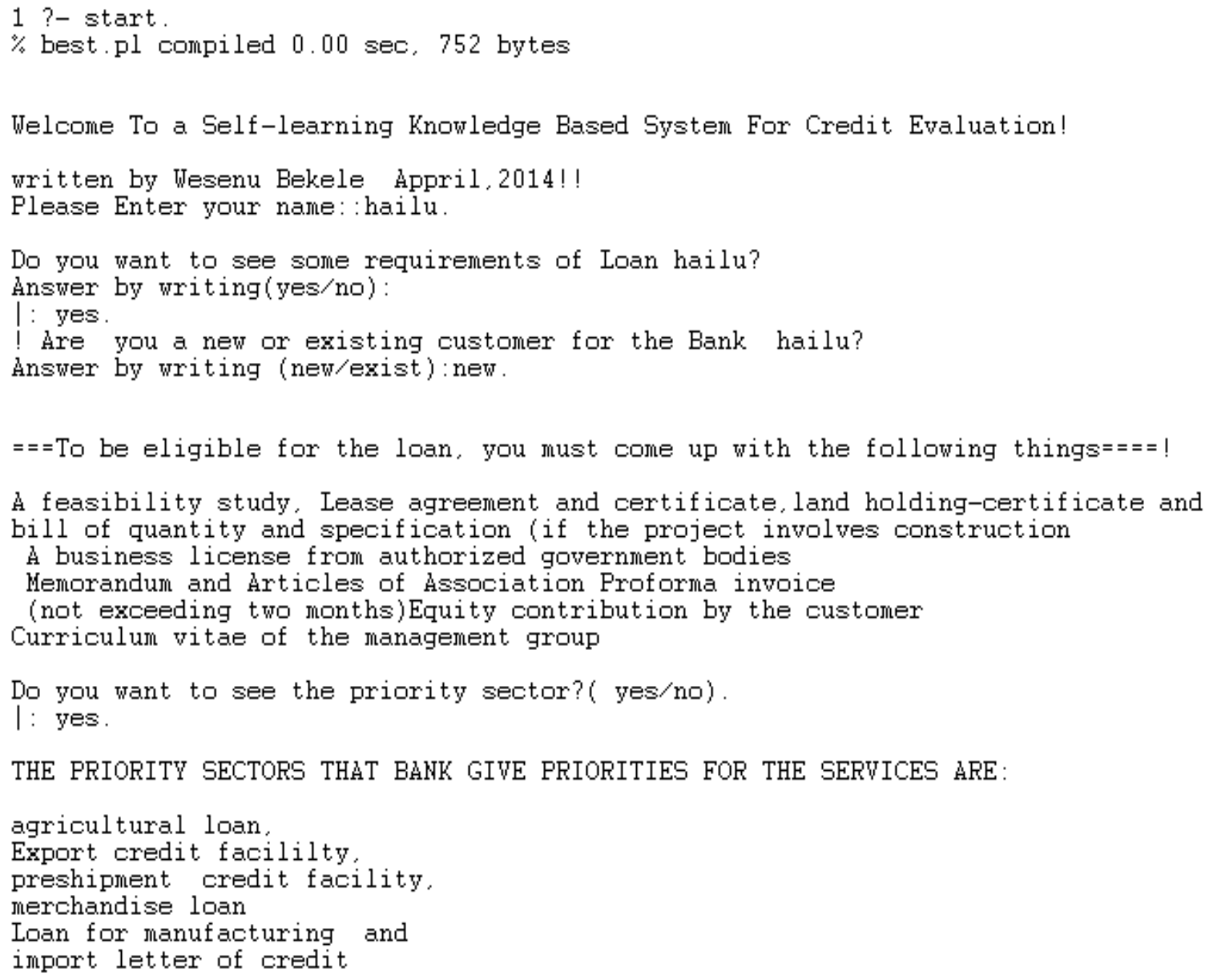

Figure 4.2. Sample dialogue windows with new customer counsel 


\subsection{Prototype System Testing and Evaluation}

Testing and evaluation of the prototype self-learning KBS is the final step that assists the knowledge engineer to measure that whether the prototype system is met the proposed objective or not.

\subsubsection{User Acceptance Evaluation}

To the problem of user acceptance, we used visual interaction along with checklist for domain experts. Six (6) loan officer where purposively selected for this purpose. Every domain expert's evaluator officer various credit customer application requests test to the prototype system and search decisions made by the prototype system. Credit customer is not participated in user acceptance evaluation, because credit customer has no right to change criteria and all requirements of credit request rather the domain experts. The domain experts evaluate the prototype system performance based on the following evaluation criteria.

These are: simplicity to use and interact with prototype system, easy to learn / adapt with prototype, prototype system efficiency in time, the involvement of adequate knowledge to evaluate requests, the ability of the prototype system to remember the customers' credit information, The ability of the prototype system in advising credit customer, and contribution of the developed prototype system in domain area. These evaluation criteria' are adapted from Solomon [17].

We set values for each attributes of the checklist for the purpose of evaluating the performance of the prototype system by credit experts. The values for all attributes are fixed as: Excellent = 5, Very good = 4, Good $=3$, Fair $=2$ and Poor $=1$.

Based on the given scale, system evaluators provide a value for each checklist. Thus, this method help us to manually examine the user acceptance based on evaluator's response. The user acceptance of the system is measured manually as follows [18]:

$$
A v e S=S V 1 * \frac{n r 1}{t n r}+S V 2 * \frac{n r 2}{t n r}+S V 3 * \frac{n r 3}{t n r}+\ldots \sum_{i=1}^{n} S V i * n r i / t n r
$$

Where, AveS Average Score, SV Scale Value, TNR Total Number of Respondent and NR is Number of Respondent. To get the result of user acceptance average performance is calculated out $100 \%$.

$$
A v p==A v e S / N S * 100
$$

Where, NS is Number of Scale and Avp is Average Performance. The following table summarizes the results obtained from the respondents. Table 4.2 indicates the results obtained after the evaluation by domain expert. The following table 4.1 illustrates the outcomes achieved after evaluation by domain experts.

\begin{tabular}{|c|c|c|c|c|c|c|c|}
\hline No. & Parameters of evaluation criteria & ஜூ & : & $\begin{array}{l}\text { D } \\
8 \\
0\end{array}$ & $\begin{array}{l}\bar{D} \\
8 \\
0 \\
0 \\
\overrightarrow{0} \\
\overrightarrow{0}\end{array}$ & 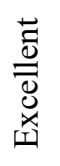 & Average \\
\hline 1 & $\begin{array}{l}\text { Simplicity to use and interactive with } \\
\text { prototype system }\end{array}$ & 0 & 1 & 1 & 2 & 2 & 3.83 \\
\hline 2 & Easy to learn / adapt with prototype & 0 & 0 & 1 & 2 & 3 & 4.33 \\
\hline 3 & Does the prototype system Efficient in a time? & 0 & 0 & 1 & 3 & 2 & 4.16 \\
\hline 4 & $\begin{array}{l}\text { Does the system include adequate knowledge to } \\
\text { evaluate requests? }\end{array}$ & 1 & 0 & 2 & 1 & 2 & 3.50 \\
\hline 5 & $\begin{array}{l}\text { The ability of the prototype system to } \\
\text { remember the customer information }\end{array}$ & 0 & 0 & 1 & 2 & 3 & 4.33 \\
\hline 6 & $\begin{array}{c}\text { The ability of the prototype system in advising } \\
\text { credit customer }\end{array}$ & 0 & 0 & 0 & 2 & 4 & 4.66 \\
\hline 7 & $\begin{array}{c}\text { contribution of the developed prototype system } \\
\text { in domain areas }\end{array}$ & 0 & 0 & 1 & 2 & 3 & 4.33 \\
\hline & & \multicolumn{5}{|c|}{ Total average } & 4.16 \\
\hline
\end{tabular}

Table 4.1. Performance evaluation by domain experts

In table 4.1above, from the evaluators who scored the simplicity to use and interact with the prototype system criteria of evaluation, $33.33 \%$ of them scored both as excellent and very good, $16.67 \%$ as good, and $16.67 \%$ as fair. In relation to easy to learn / adapt with the prototype system criteria of evaluation, $50 \%$ of the evaluators scored as excellent, and $33.33 \%$ as very good and $16.67 \%$ as good. The criteria of evaluation with respect to the prototype system efficiency in time, was evaluated by $33.33 \%$ as excellent, by $50 \%$ as very good and by $16.67 \%$ as good. In the case of fifth criteria of evaluation, i.e., whether or not the prototype system include adequate 
knowledge to evaluate requests or application, the it was scored by $33.33 \%$ as excellent, by $16.67 \%$ as very good, by $50 \%$ as good and by $16.67 \%$ as poor. The evaluation criteria with respect to the ability of the prototype system to remember the customer's information was rated by half $(50 \%)$ of the evaluators as excellent, by $33.33 \%$ as very good and by $16.67 \%$ as good. At the side of, the ability of the prototype system in advising credit customer, $66.67 \%$ of the evaluators scored the prototype system "excellent" and $33.33 \%$ of them "very good".

The final evaluation criteria, i.e., concerning the contribution of the developed prototype system in domain area, half $(50 \%)$ of the evaluators rated "excellent", $33.33 \%$ of them "very good" and $16.67 \%$ of them "good". Finally, the average performance of the prototype system according to the evaluation results filled by the domain experts is 4.16 out of 5 . This result indicates that the overall average performance of the prototype self-learning KBS is about $83.2 \%$. This implies that the modeled prototype was performs well in making right evaluation on the credit evaluation of customer application.

\subsubsection{Prototype System Performance Testing}

Performance testing is the process of determining whether the developed prototype system is valid or invalid, that is whether it achieves the required level of accuracy or not. To address the issue of validation, eighteen (18) test cases were used from CBE credit application. For the test, three types of cases were selected purposively. These cases are overdraft credit facility, import letter of credit facility and pre-shipment export credit facility. For these tests (6 from each type) test cases were select for testing cases. Half of them selected from the requests or applications that are evaluated as ineligible by human expert and the rest of them from the requests evaluated as eligible by domain experts. The reasons for taking both ineligible and eligible test cases that evaluated by domain experts are to check the correctness evaluation from both sides. For each case three test cases from ineligible requests and three of them from eligible requests or applications were selected. So that, each case has equal number of test cases from both ineligible and eligible credit customer applications or requests.

Additionally, six domain experts or credit evaluators were selected to evaluate the developed prototype system by interacting with the developed prototype. These evaluators have participated in the user acceptance evaluation. The reason why domain experts were selected for the second time was that they are familiar with the system prototype during visual interaction evaluation. So, they can easily understand about the prototype. Table 4.2 below shows the test results found by test cases.

Table 4.2. Testing the accuracy of prototype system using testing

\begin{tabular}{ccccc} 
Selected cases & $\begin{array}{c}\text { Total number of cases } \\
\text { selected for testing }\end{array}$ & $\begin{array}{c}\text { Number of correctly } \\
\text { evaluated cases }\end{array}$ & $\begin{array}{c}\text { Number of incorrectly } \\
\text { evaluated cases }\end{array}$ & Accuracy \\
\hline $\begin{array}{c}\text { Overdraft credit } \\
\text { Facility }\end{array}$ & 6 & 5 & 1 & $83.33 \%$ \\
$\begin{array}{c}\text { Import letter of } \\
\text { Credit facility }\end{array}$ & 6 & 4 & 2 & $66.67 \%$ \\
$\begin{array}{c}\text { Pre-shipment } \\
\text { Export credit }\end{array}$ & 6 & 4 & 2 & $66.67 \%$ \\
\hline Total & 18 & 13 & 5 & $\mathbf{7 2 . 2 2 \%}$ \\
\hline
\end{tabular}

During the testing procedure, the selected experts evaluated and identified correctly and incorrectly evaluated cases by comparing the decision made by the prototype system with that of the experts' decision on those cases. As shown in table 4.2 above, the highest accuracy rate is obtained by case of overdraft credit facility. The same results were achieved for both import letter of credit facility and pre-shipment export credit facility which is less accurate than overdraft credit facility. The overall results of the testing have revealed $72.22 \%$ accuracy in evaluating the evaluation of customer loan request.

\subsubsection{Discussions}

As shown in the above table 4.2 and 4.1 , the accuracy of the prototype system calculated is $72.22 \%$ and the average user performance evaluation results filled by the domain experts in the domain fields is $83.2 \%$, respectively. In general, the overall performance of the prototype system is $77.71 \%$.Kay Bryant [5], has done research study on the integration of qualitative factors into ES for evaluating agricultural loans. The researcher used dependency diagram to represent knowledge. The developed ES enables the loan officer's to make decision easily in agricultural loan evaluation. The researcher achieves $73 \%$ performance of the developed system.

As comparing to the result found by Kay Bryant [5] with the result of this study, the result found in this study is better than the result found by Kay Bryant [5]. The performance achieved by this study is greater than the work of Kay Bryant [5] by $4.71 \%$ performances. This can be resulted because the method of knowledge modeling and method of knowledge representation. So that, it is better to use decision tree for knowledge modeling and rule base for knowledge representation.

During this study, starting from the beginning to the end, we were face a lot of challenges. These challenges are discussed as follows.

* Building the KBS is not an easy task. To build this, tacit and explicit knowledge must be extracted 
from the domain experts as well as from different sources of knowledge that help to develop the prototype self-learning KBS for loan evaluation. To do this, extracting tacit knowledge from the domain experts is very difficult due to the personal nature of tacit knowledge. Besides, extracting tacit knowledge is by itself hard to reveal to others. So, we faced difficulty to extract or to obtain the tacit knowledge of credit evaluators.

* The main factor that hinders the prototype system to register higher accuracy is that the attitudes of the domain experts' credit evaluators since there is no similar KBS for credit evaluator or advisory system in banking industry and micro financial institutions in Ethiopia are adopted currently.

\& During coding the represented knowledge about credit evaluation using the SWI-prolog editor tool, the facts base of the prototype system is able to update its knowledge automatically. However, we faced a challenge to update the rules of the knowledge base of the prototype system automatically.

Depending on the results found, the main strength of the prototype system and its applicability in the domain areas are:

$>$ The prototype self-learning KBS helps to solve problems in the domain areas where an experienced and skilled man power are unavailable as well as helps to reduce inconsistence.

$>$ The prototype system has the capability to learn the histories of credit customer from the experience and updates the knowledge.

$>$ The prototype is system applicable everywhere.

$>$ Prototype system stores the facts in fact base or database which helps to remember easily during credit evaluation.

Generally, all the evaluation and testing results of the prototype show encouraging finding for further research work to fully implement and apply self-learning KBS technology in credit evaluation in banking industry and micro financial institutions. As a result, from the study findings, it is possible to conclude that the study achieve its objectives.

\section{Conclusion and Recommendations}

\subsection{Conclusion}

ES play a major role in resolving different problems in credit evaluation. In recent years, tools, technologies and applications of information technologies have emerged as effective and efficient measures for up gradation of the whole banking industries. In this paper, an attempt has been made to design and develop a prototype of a selflearning KBS that can provide an advice for credit customer and credit evaluators to facilitate the evaluation of customer application or requests for the loan.

In developing the prototype system, knowledge is acquired using semi-structured interviews with domain experts and from relevant documents like credit evaluation procedure by using document analysis method to find the solution of the problem. The acquired knowledge is modeled using decision tree that models concepts and procedures involved in credit evaluation. After that, the validated knowledge is represented using rule-based knowledge representation technique and implemented using SWI-prolog develop tools for developing the prototype self-learning KBS to provide advisory services both for customer(new and existing customer) and assists domain experts in applications evaluation.

Also, in testing and evaluation of the prototype system, eighteen (18) cases of credit request or application are selected using purposive sampling method in order to test the accuracy of the prototype system. The selected cases include both cases that are evaluated as ineligible and eligible by human experts. The selection is equal for both of them, i.e. nine (9) of cases are eligible cases and the rest of them are ineligible cases. The correct and incorrect evaluation results are identified by comparing the decision made by the evaluators on the cases credit applications and with the conclusions of the prototype system. And also the process of ensuring that the prototype system satisfies the requirements of the user is performed. As the testing results show, the overall performance of the prototype system registers $77.71 \%$.

Furthermore, the study concludes that the major credit production type that advanced to customer is import letter of credit facility, export credit facility, pre-shipment credit facility and merchandise. The eligibility of application is focused on general and specific criteria. Credit customer is classified as business, corporate and commercial based on the score sheet they achieved.

Generally, in this study, the applicability of knowledge of prototype self-learning KBS is proved as helpful approach in banking industry for credit evaluation.

\subsection{Recommendations}

We recommended that the following challenges are future works based on this study.

\& In this study the explanation facility given by the proposed system is not user friendly. So, further research can be done to add interactive user interface that can help the user to interact with the system.

* Due to time limitation, this study attempted to develop a self-learning KBS for credit evaluation. However, 
the scope of the self-learning KBS should be extended to include other credit production type such as term loan, agricultural loan and consumer loan. Therefore, further investigation should be done on term loan, agricultural and consumer loan.

* The scope of the prototype is limited to evaluating credit production type based on general and specific eligible criteria and credit customer classification. For credit analysis and scoring detail evaluation of application are required. Therefore, the further work should be done on credit analysis and credit scoring.

\section{Conflict of Interest}

The authors declare no conflicts of interests regarding the publication of this paper.

\section{References}

[1] Tibebu T.," Credit Risk Management and Profitability of Commercial banks in Ethiopia", MA Thesis, Addis Ababa University School of business and Public administration Department of Accounting and Finance, Ethiopia, 2011.

[2] Credit Eva+6luation and Approval, Available At: http://www.inc.com/encyclopedia/credit-evaluation-andapproval.html,Accessed Date: November 21, 2013.

[3] A. JASIŃSKI, “Credit Expert: expert system for Credit applications evaluation”, Interdisciplinary research, University of Lodz, Faculty of Management, Poland, 2000.

[4] V. Pacelli1 and M. Azzollini,"An Artificial Neural Network Approach for Credit Risk Management", Intelligent Learning Systems and Applications, Vol.3, No.2, PP. 103-112, 2011.

[5] K. Bryant, "The integration of Qualitative factors into Expert Systems for evaluating Agricultural loans" Griffith University, Brisbane, Australia, 1999.

[6] Pomykalski, J.J., Truszkowski, W.F. and Brown, D.E.,'Expert Systems”, in Wiley encyclopedia. USA: J. Webster. Pp. 1-66, 1999.

[7] J. Nassali,"A Loan Assessment System for Centenary Rural Development Bank", Master of Science in Computer Science, Makerere University Faculty of Computing and Information Technology, Uganda, 2005.

[8] Y. Shao and C., Oppenheim, "Expert System in Banking : The British Scene" A Preliminary Report, Department of Information Science, Strathclyde Business School, University of Strathclyde, 26 Richmond Street, United Kingdom.

[9] Desalegn K.,'Designing aknowledge based system for VAT Administration", MSc Thesis, Addis Ababa University School of Information Science, Ethiopia, 2009.

[10] Wondimagegnehu N., "Determinants of nonperforming Loans: The case of Ethiopian Banks",MA Thesis, University of south Africa( UNISA),School of Business Leadership, South Africa 2012.

[11] Shalfield, R.," LPA WIN prolog user guides.” Logic Programming Associates, England, 2002.

[12] Martin O., "credit assessment process and repayment of bank loans in barclays bank Uganda ltd", MBA Thesis, Makerere University Business School (MUBS), Uganda, June 2007.

[13] K. Tripathi,"A Review on Knowledge-based Expert System: Concept and Architecture", IJCA Special Issue on "Artificial Intelligence Techniques - Novel Approaches \& Practical Applications", BharatiVidyapeeth Deemed University Institute of Management Kolhapur, India, AIT, 2011.

[14] Pfenning F.,'Logic Programming", Carnegie Mellon University, 2007.

[15] Covington M.,"Prolog Programming in Depth", Artificial Intelligence Programs The University of Georgia, U.S.A, 1995.

[16] E. Turban, J. E. Aronson and Liang, "Decision Support Systems and Intelligent Systems", $7^{\text {th }}$ ed., Prentice Hall, Upper Saddle River, 2001.

[17] Solomon G., "A self-learning Knowledge Based System for Diagnosis and Treatment of diabetes", MSc Thesis, Addis Ababa University School of Information Science, Ethiopia, 2013.

[18] R. Lakner "Knowledge-based systems",Engineering Application of AI-PhD Course,Department of Computer Science,University of Veszprém, Hungary, 2001. 